\title{
Delayed Presentation of Patients with Gynaecological Malignancies in Kano, North-Western Nigeria
}

\author{
Natalia Adamou*, Usman Aliyu Umar \\ Bayero University/AKTH, Kano, Nigeria \\ Email: ${ }^{*}$ drnataliarmu@yahoo.com
}

Received 20 May 2015; accepted 14 June 2015; published 17 June 2015

Copyright (C) 2015 by authors and Scientific Research Publishing Inc.

This work is licensed under the Creative Commons Attribution International License (CC BY). http://creativecommons.org/licenses/by/4.0/

(c) (i) Open Access

\section{Abstract}

The diagnosis and management of gynaecological cancers are still challenging in low- and middleincome countries. In patients with gynaecological malignancies delay at any point increases morbidity and mortality. This study evaluated the factors that may delay presentation, diagnosis and treatment of patients with malignant gynaecological cancers, and described the duration of each delay. It was a prospective cross-sectional study. A total number of 96 patients diagnosed to have gynaecological malignancy were enrolled in the study between the April 2014 and April 2015. The median age was 47.5 years (range of 18 - 84 years). The diagnoses on admission were cervical malignancy $34(35.42 \%)$, ovarian malignancy 32 (33.33\%), chorio carcinoma 15 (15.63\%), cancers of uterine body (endometrial and leiomyosarcoma) $10(10.42 \%)$ and vulval malignancies 5 (5.2\%). Majority of the patients $65(67.7 \%)$ presented late at either stage III or IV. At presentation, 36 patients $(37.5 \%)$ had severe anaemia; 10 patients $(10.41 \%)$ had obstructive uropathy; $3(3.13 \%)$ developed fistula; $19(19.79 \%)$ died on admission from complication of their disease. Most patients 61 (63.54\%) had delayed presentation of more than 90 days ("patients delay"). Time in decision ranged between 3 days to maximum of 2920 days and median of 150 days. 58 (60.42\%) gave a reason for such delay as lack of knowledge of their presenting symptoms, as a warning sign of possible malignancy; 80 (83.33\%) had delay in diagnosis ("doctor delay"); $40(41.67 \%)$ reported that the medical practitioner did not make referral to the center with available gynaecological services; "hospital delay" was observed in $66(68.75 \%)$ of patients. The reason for delayed treatment in $35(36.46 \%)$ of patients was severe patients condition that warrant stabilization (blood transfusion and dialysis) and $29(30.21 \%)$ could not afford the treatment. Late presentation is a great problem in the management of oncological patients in this environment. High cost of care is the major challenge for the patients and gynaecologist in north-western part of Nigeria.

*Corresponding author.

How to cite this paper: Adamou, N. and Umar, U.A. (2015) Delayed Presentation of Patients with Gynaecological Malignancies in Kano, North-Western Nigeria. Open Journal of Obstetrics and Gynecology, 5, 333-340.

http://dx.doi.org/10.4236/ojog.2015.56048 


\section{Keywords}

\section{Delayed Presentation, Gynaecological Cancers, Nigeria}

\section{Introduction}

Gynaecological malignancy is a major cause of in-hospital death [1]. Developing countries accounted for 820,265 cases (77.7\%) of global estimates for new cases of the commonest gynaecological cancers [2] [3]. In Nigeria squamous cell carcinoma of the cervix is the commonest gynaecological malignancy followed by ovarian cancers [4]. Carcinoma of the ovary is the fourth most common cancer among women and continues to be a leading cause of death from gynaecological malignancies worldwide [5]. Most patients with ovarian malignancies presents late to the hospital. The developing countries have only $5 \%$ of global resources for cancer control and limited means of treatment [6].

The diagnosis and management of gynaecological cancers are challenging in low- and middle-income countries (LMIC). Patients often present with non-specific symptoms and diagnosis is generally made when the disease has advanced [7]. When diagnosed in early stages, the interventions are often curative with a minimal impact on quality of life, while interventions in advanced stages are associated with drug resistance and complications. Care in late presentation is generally palliative and aim at controlling tumor growth and progression or relieving symptoms. It affects quality of life and carry poorer prognosis. The majority of patients diagnosed with advanced cancer have five-year survival of only $28 \%$ [8].

"Patient delay" refers to the period (number of days) between an individual's first awareness of illness (signs and symptoms) and medical consultation and diagnosis [9]. It can occur at many phases. The first phase is the interval between when a patient first noticed a symptom and first consultation with a doctor ("patient delay"); second phase is the time between first consultation and referral by a practitioner("doctor or practitioner delay") and the third phase is between referral and diagnosis("hospital or system delay") [8]-[10].

\section{Justification of the Study}

In patients with gynaecological malignancies delay at any point increases morbidity and mortality. Therefore reducing delay can lead to early diagnosis when cure is likely, a better five-year survival, longer disease free interval and better quality of life.

Patient education is essential to assist with early diagnosis. If women are aware of the signs and symptoms of common gynaecological malignancies, they will present earlier for diagnosis, which improve survival. Also awareness of available diagnostic methods and understanding diagnostic process by general practitioner at the first point of presentation will help in early diagnosis and referral of the patients.

The possible causes of delays that may influence on patients presentation, diagnosis, treatment and survival with malignant cancers were not evaluated in our center and other centers in Nigeria (to the best of authors' knowledge based on available published studies). Therefore, this study set out to evaluate whether women diagnosed to have malignant gynaecological cancers experienced delay in presentation, diagnosis or treatment.

\section{Methodology}

This study was conducted at Aminu Kano Teaching Hospital (AKTH), which was established in 1988. It is affiliated to Bayero University, Kano. It is located in Kano city, the capital of the Northwestern Nigerian state of Kano. AKTH is one of the tertiary health facilities in Kano and patients from other hospitals and clinics are referred here. It also serves as referral center for the other neighboring states of Bauchi, Katsina and Jigawa. The gynaecological ward contains 22 beds. This was a prospective cross-sectional study. This study evaluated the factors that may delay presentation, diagnosis and treatment of patients with malignant gynaecological cancers, described the length of each delay and recommend strategies that may reduce the delays.

The study sample size was calculated using the formula: $N=z^{2} p q / E^{2}(N-$ minimum sample size, $z-1.96$ (standard normal deviate for normal 95\% confidence interval level), $p$-proportion of population with condition studied $(94 \%)^{2}, q$-complementary probability $(100-p)=(100-94)=6 \%, E$-precision required (tolerable 
sampling error) $=5 \%$.

Therefore: $N=(1.96)^{2}(94 \%)(100-94) / 5^{2}=86.6$. Given attrition rate of $10 \%: 86.6+10 / 100(86.6)=95.7$. Approximately 96 patients were required for this study.

Newly diagnosed patients (clinically and pathologically) with malignant gynaecological cancer admitted to the gynaecological oncology unit were included in this study. Patients without pathological diagnosis, with recurrent disease, with readmission, who did not consent to participate into study, mentally disable and unconscious patient were excluded. Eligible newly diagnosed patients admitted to the gynaecological oncology unit, who consented to participate in the study were consecutively recruited using convenience sampling until the required sample size was obtained. Pre-tested interviewer administered questionnaires were used to obtain information on socio-demographic characteristics. The patients were asked to identify the three critical calendar dates in delay time of three stages of delay. The three dates were: 1) the date when first symptoms were detected and she decided to seek medical care ("patient delay"), 2) the date the patient presented to the hospital and had first diagnosis (the number of days elapsed from date 1 to date 2-“doctor delay"), 3) the date she had referral or treatment (the number of days elapsed from date 2 to date 3- "hospital or system delay”). Total patient delay was defined as the sum of those stages of delay. In the study we used definitions: delayed presentation was defined as patient duration of symptoms $\geq 3$ months, provider delay, as referral delay of $\geq 6$ weeks after first attendance and hospital delay, as delay of $\geq 6$ weeks after referral [11].

Questionnaires were used to evaluate duration of delay and reason for it at each stage. Diagnostic and medical information was obtained from participants, hospital documentation and physicians.

Interview was scheduled on the day before beginning of treatment. All women were interviewed individually.

All data generated was checked and analyzed using computer based EPI Info version 7.0.9.34 software. Quantitative variables were described using mean and standard deviation. Qualitative variables were presented as percentages. Chi-square or Fisher's exact test were used for assessing the significance of associations between categorical groups. A P-value of $<0.05$ was considered statistically significant.

Information obtained from the study and findings from the data analysis was presented in tabular, graphical and diagrammatical forms using different variables.

Approval for the study was obtained from the ethics committee of AKTH, Kano.

Approval was sought to interview and manage the patients admitted to the gynaecological ward under oncology unit. No patient was forced to participate in this study against her wish. Participation was entirely voluntary. A verbal consent was obtained after the nature of the study, the aims and objectives and the protocol were clearly explained to patients. The names of the subjects did not appear on the questionnaires. A code number was assigned to each patient.

\section{Results}

A total number of 96 patients diagnosed to have gynaecological malignancy were enrolled in the study between the April 2014 and April 2015. Patients without pathological diagnosis with recurrent diseases or readmission were excluded from the study.

Table 1 represents the socio-demographic data and revealed medical histories of the participants. The median age was 47.5 years, with age range of $18-84$. The mean parity was 6.05 (SD \pm 4.15 ) and mean age of menopause was $48.76(\mathrm{SD} \pm 4.79)$ and $51(53.13 \%)$ of women were menopausal.

The vast majority of patients 34 (35.42\%) were in the age group between 39 - 58 years. Married women constituted $75 \%$ of the study population and $53.13 \%$ had no formal education. The diagnoses on admission were cervical malignancy 34 (35.42\%), ovarian malignancy 32 (33.33\%), chorio carcinoma 15 (15.63\%), cancers of uterine body (endometrial and leiomyosarcoma) 10 (10.42\%) and vulval malignancies 5 (5.2\%) (Figure 1). Majority of the patients (67.7\%) presented late at either stage III or IV (Figure 2). At presentation, 36 patients (37.5\%) had severe anaemia, 10 patients (10.41\%) had obstructive uropathy, 3 (3.13\%) developed fistula, 19 (19.79\%) died on admission from complication of their disease and 28 (29.17\%) of patients had no complications.

Most patients 61 (63.54\%) had delayed presentation of more than 90 days ("patients delay"). Time in decision ranged between 3 days to maximum of 2920 days and median of 150 days). Majority of patients 58 (60.42\%) gave a reason for such delay as lack of knowledge of their presenting symptoms as a warning sign of possible cancer, $9(9.38 \%)$ tried traditional medications prior to presentation, 12 (12.5\%) denied the possibility of cancer and $14(14.58 \%)$ delayed in decision to present to the hospital in their thoughts without any reason. 
Table 1. Socio-demographic characteristics of the participant.

\begin{tabular}{cc|}
\hline Variable & \\
\hline Mean age (years) & $47.94(\mathrm{SD} \pm 16.39)$ \\
Mean parity & $6.05(\mathrm{SD} \pm 4.15)$ \\
Mean age at menarche (years) & $14.4(\mathrm{SD} \pm 1.39)$ \\
Mean age of menopause (years) & $48.76(\mathrm{SD} \pm 4.79)$ \\
Mean duration of symptoms (days) & $502.34(\mathrm{SD} \pm 602.33)$ \\
Mean time prior to presentation (days) & $349.18(\mathrm{SD} \pm 463.48)$ \\
Mean time before final diagnosis (days) & $203.03(\mathrm{SD} \pm 223.22)$ \\
Mean time prior treatment (days) & $190.15(\mathrm{SD} \pm 225.27)$ \\
\hline Variable & \\
\hline Education & \\
\hline None & $51(53.13 \%)$ \\
Islamic & $14(14.58 \%)$ \\
Primary & $12(12.50 \%)$ \\
Secondary & $12(12.50 \%)$ \\
Higher & $7(7.29 \%)$ \\
Total & $\mathbf{9 6} \mathbf{( 1 0 0 \% )}$ \\
\hline
\end{tabular}

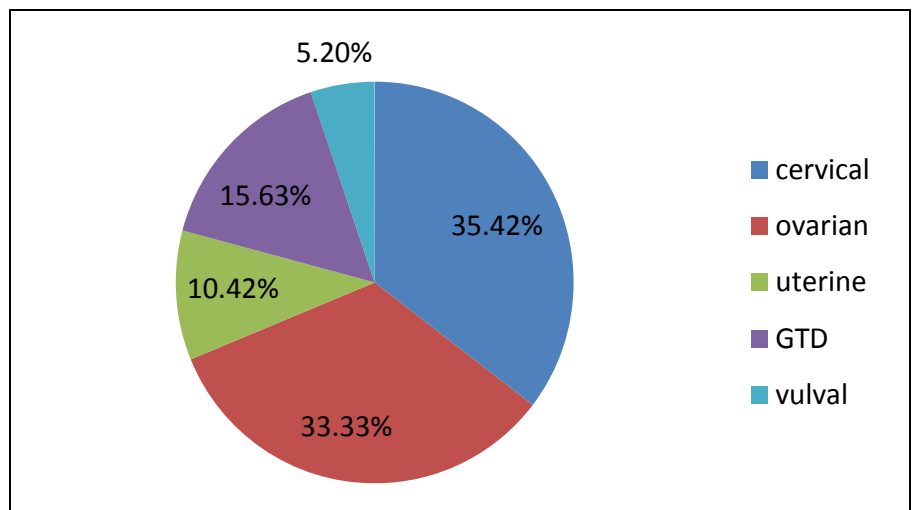

Figure 1. Admission diagnoses. The admission diagnoses were cervical malignancy 34 (35.42\%), ovarian malignancy 32 (33.33\%), chorio carcinoma 15 (15.63\%), cancers of uterine body (endometrial and leomyosarcomas) 10 (10.42\%) and vulval malignancies 5 (5.2\%).

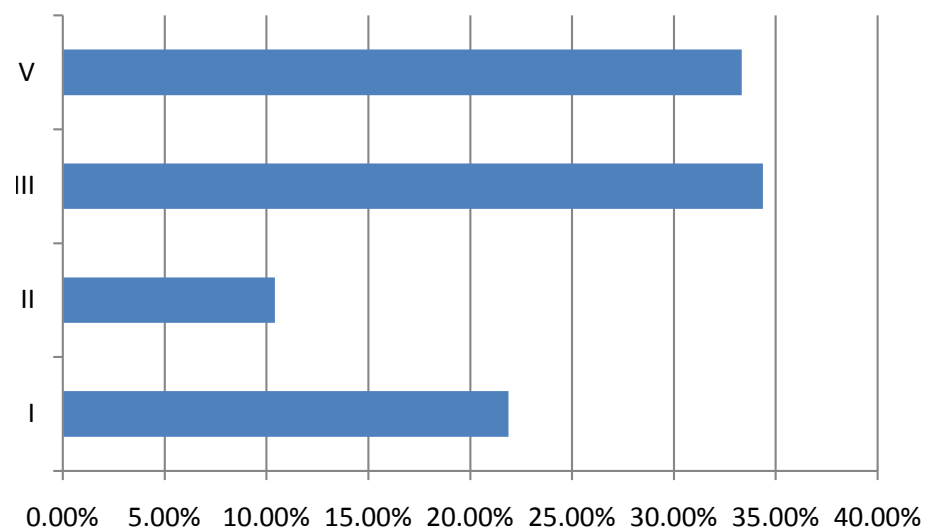

Figure 2. Stage of the diseases. The majority of patients presented at stage III $33(34.37 \%)$ and IV 32 (33.33\%). stage I 21 (21.88\%) and stage II 10 (10.42\%). 
The majority of patients 80 (83.33\%) had delay in diagnosis(“doctor delay”), 40 (41.67\%) reported that the medical practitioner did not make referral to the center with available gynaecological services, 24 (25\%) were missed diagnosed by a medical practitioner elsewhere, 11 (11.46\%) complained of financial reason, 11(11.46\%) still denied the condition, 2 (2.08\%) tried traditional medications and 8 (8.33\%) mentioned industrial(hospitals) strike as the reason for delayed diagnosis.

"Hospital delay" was observed in 66 (68.75\%) of patients, only 30 (31.25\%) of patients received the treatment within 6 weeks of diagnosis. The reason for delayed treatment in $35(36.465 \%)$ of patients was severe patients condition that warranted stabilization (blood transfusion and dialysis), 29 (30.21\%) could not afford the treatment, 16 (16.67\%) patients delayed the treatment as result of industrial strike and 11 (11.46\%) of patients denied the treatment. Data was displayed in Table 2.

No statistically significant association between patient's age, stage of disease, education and the time of first presentation was found (Table 3).

\section{Discussion}

This study described three major delays in diagnosis of gynaecological cancers during the study period. The study demonstrated that our patients presented in advanced stages of their illness (stage III/IV). The mean time prior to first presentation was 349.18 ( $\mathrm{SD} \pm 463.48$ ) days with mean duration of symptoms 502.34 (SD \pm 602.33 ) days. Patients stated lack of knowledge as the main reason for delayed presentation. Patients waited 11.6 months before the first medical practitioner consultation, which is the most important contributor to delayed diagnosis. It represents poor primary health education of the patients. The majority of our patients 51 (53.13\%) have no formal education. Patients are generally asymptomatic in the early stage of disease with symptoms appearing as cancer

Table 2. Delays.

\begin{tabular}{|c|c|c|c|}
\hline Delay in days & Number of patients (\%) & Reason for the delay & Number of patients (\%) \\
\hline \multicolumn{4}{|l|}{ "Patients delay" } \\
\hline No delay & $35(36.46 \%)$ & Delay in decision & $14(14.58 \%)$ \\
\hline \multirow{4}{*}{ Delay } & \multirow{4}{*}{$61(63.54 \%)$} & Lack of knowledge & $58(60.42 \%)$ \\
\hline & & Denial & $12(12.50 \%)$ \\
\hline & & Financial & $3(3.12 \%)$ \\
\hline & & Traditional drugs & $9(9.38 \%)$ \\
\hline Total & 96 (100\%) & Total & $96(100 \%)$ \\
\hline \multicolumn{4}{|l|}{ “Doctor Delay” } \\
\hline \multirow[t]{3}{*}{ No delay } & $16(16.67 \%)$ & Patient denial of diagnosis & $11(11.46 \%)$ \\
\hline & & Patient's financial status & $11(11.46 \%)$ \\
\hline & & Missed diagnosis & $24(25 \%)$ \\
\hline \multirow[t]{3}{*}{ Delay } & $80(83.33 \%)$ & Delay referral & $40(41.67 \%)$ \\
\hline & & Hospital strike & $8(8.8 .33 \%)$ \\
\hline & & Traditional drugs & $2(2.08 \%)$ \\
\hline Total & $96(100 \%)$ & Total & $96(100 \%)$ \\
\hline \multicolumn{4}{|l|}{ “Hospital delay" } \\
\hline \multirow[t]{3}{*}{ No delay } & $30(31.25 \%)$ & Delayed pathology & $6(6.25 \%)$ \\
\hline & & Traditional drugs & $2(2.08 \%)$ \\
\hline & & Denial & $11(11.46 \%)$ \\
\hline \multirow[t]{3}{*}{ Delay } & $66(68.75 \%)$ & Patients condition & $35(36.46 \%)$ \\
\hline & & Finance & $29(30.21 \%)$ \\
\hline & & Strike & $13(13.54 \%)$ \\
\hline Total & $96(100 \%)$ & Total & $96(100 \%)$ \\
\hline
\end{tabular}


Table 3. Association between age, stage, education and time of first presentation.

\begin{tabular}{|c|c|c|c|}
\hline Age & No delay (<90 days) & Delay ( $\geq 91$ days) & Total \\
\hline Non-menopausal & $23(23.96 \%)$ & 27 (28.13\%) & $50(52.08 \%)$ \\
\hline Menopausal & 19 (19.79\%) & 27 (28.13.7\%) & 46 (47.92\%) \\
\hline Total & $42(43.75 \%)$ & $54(56.25 \%)$ & $96(100 \%)$ \\
\hline \multicolumn{4}{|c|}{$X=0.2147, D f=1, P=0.6431$} \\
\hline Stage & No delay (<90 days) & Delay ( $\geq 90$ days) & Total \\
\hline $\mathrm{I} / \mathrm{II}$ & $17(40.48 \%)$ & $25(59.52 \%)$ & $42(100 \%)$ \\
\hline $\mathrm{III} / \mathrm{IV}$ & $14(25.95 \%)$ & $40(74.07 \%)$ & $54(100 \%)$ \\
\hline Total & 31 (32.29\%) & $65(67.71 \%)$ & $96(100 \%)$ \\
\hline \multicolumn{4}{|c|}{$X=2.29, D f=1, P=0.13$} \\
\hline Education & No delay (<90 days) & Delay ( $\geq 90$ days) & Total \\
\hline None & $28(29.17 \%)$ & 37 (38.54\%) & $65(67.71 \%)$ \\
\hline Educated & $14(14.59 \%)$ & $17(17.71 \%)$ & 31 (32.29\%) \\
\hline Total & $42(43.76 \%)$ & $54(56.25 \%)$ & $96(100 \%)$ \\
\hline$X=0.0371, D f=1, P=$ & & & \\
\hline
\end{tabular}

progresses. In cervical and endometrial cancers the presence of postmenopausal or post coital bleeding is earlier manifestation compared to patients with ovarian cancer, where symptoms are non specific with insidious onset leading to delay in presentation and diagnosis. Educating our women on symptoms of gynaecological malignancies and health risks can reduce denial and ignorance of our patients and may help in earlier presentation to the medical facility. Though, this study did not find any statistically significant association between education, age, stage and the time of first presentation, there is still need to evaluate further, health education of the our women on awareness of deadly diseases, which can reduce patient's denial and ignorance. Denial of evaluation of first symptoms and delay in decision to attend the hospitals in this environment is also influenced by female status in the family and financial dependence. It contribute to fair, delay in complaining to her husband or relatives, finally choosing not to report or trying traditional medications as thought to be an alternative and cheaper form of care.

Knowledge and awareness on symptoms and signs of these malignancies by the medical practitioners is also very important, as the main reason for delayed diagnosis observed were delayed referral and missed diagnosis by general practitioners 40 (41.67\%) and 24 (25\%) retrospectively. "Doctors delay" contributed to further 6.7 months of delay in patient's evaluation. It can be also contributed by poor coverage of the patients by preventive screening programs that could detect disease at early stage. In Kano state, for example, only three centers are available to screen 4.45 millions of females of one the largest state in Nigeria with population of 9.3 millions. There are 176 cancer screening centers in Nigeria with population of 162,471 million and $49.36 \%$ of female population [12]. Studies conducted in Southeast of Nigeria demonstrated that only $0.6 \%-11.5 \%$ of women had ever been screened [13] [14].

The major challenge in reduction of delay prior to treatment includes availability of well equipped centers to manage these patients properly, in Nigeria. Only few centers in Nigeria have functional radiotherapy facility. For example, in our center this facility is not yet available and it make our referral very difficult to the patients, as it demand extra recourses(finance), logistics(organization of transportation and accommodation) and finally rejection of advocated treatment, loss from follow up and presentation at advanced stage when only palliation is possible, while patients are still awaiting cure. Financial aspect was the second major factor that contributed to delay in management of our patients 20 (30.21\%). Compared to the management of oncological patients in developed countries the management in Nigeria of oncological patient is not covered by national insurance scheme. Diagnosis, surgery, chemotherapy and radiation therapy are very expensive to our patients. In our hospital, patients can only have reduction in the bill by contributing financial assistance by Islamic organization and "hospital friends'-people that voluntarily donate money to help poor people. But even then patients are unable to sustain the treatment. So, government still has a role to play in the management of oncological patients despite that patients have deadly disease and poor 5 years survival. 
The other challenge during the period of study observed was hospital strike: twice in 2014/2015: two and three months strike July/August and November-January respectively that affected hospital work.

\section{Conclusion}

Cervical, ovarian and endometrial malignancies are the most frequent malignancies diagnosed in this environment. Late presentation is a great problem in management of oncological patients. The reasons for such delays are multifactorial. High cost of care is the major challenge for the patients and gynaecologists in the northern part of Nigeria.

\section{Recommendations}

1) Health education of women on cancer symptoms through media, political and religious leaders and schools.

2) Training of general practitioners.

3) Training of nurses, gynaecologists on oncology care.

4) Multidisciplinary team approach to treatment of patients with gynaecological cancers.

5) To propose establishment of radiotherapy unit in our facility

6) Coverage of management of oncological patients by NHIS or to have subsidy by government.

\section{Limitations}

This study did not represent all women of Kano State diagnosed to have gynaecological malignancy.

\section{References}

[1] Ibrahim, S.A., Natalia, A., Abubakar, I.S. and Garba, I.D. (2011) Pattern of Gynaecological Admissions in Aminu Kano Teaching Hospital: A Three Year Review. Tropical Journal of Obstetrics and Gynaecology, 28, 145-150.

[2] Iyoke, C.A., Ugwu, G.O., Euzebus, C.E., Frank, O.E., Osaheni, L.L. and Azubuike, K.O. (2014) Challenges Associated with the Management of Gynaecological Cancers in a Tertiary Hospital in South East Nigeria. International Journal of Women's Health, 6, 123-130. http://dx.doi.org/10.2147/IJWH.S55797

[3] Iyoke, C.A. and Ugwu, G.O. (2013) Burden of Gynaecological Cancers in Developing Countries. World Journal of Obstetrics and Gynecology, 2, 1-7. http://dx.doi.org/10.5317/wjog.v2.i1.1

[4] Galadanchi, H.S., Mohammed, A.Z., Uzoho, C.C. and Jido, T.A. (2003) Gynaecological Malignancies Seen in a Tertiary Health Facility in Kano, Northern Nigeria. Tropical Journal of Obstetrics and Gynaecology, 20, 105-108.

[5] Odukogbe, A.A., Adebamowo, C.A., Ola, D., Olayemi, O., Oladukun, A., Adawole, I.F., et al. (2004) Ovarian Cancer in Ibadan: Characteristics and Management. Journal of Obstetrics Gynaecology, 24, 294-297. http://dx.doi.org/10.1080/01443610410001660904

[6] Mohamed, A.Z., Galadanchi, H.S., Ochicha, O., Omale, A.E. and Jido, T.A. (2002) Cytopathological Findings on Cervical Smears in Aminu Kano Teaching Hospital, Kano. J Med Associate Niger, 1, 51-53.

[7] Hanoch, J. (2005) Improving the Prognosis of Ovarian Cancer. In: Studd, J., Ed., Progress in Obstetrics and Gynaecology, Elsevier, Amsterdam, 357-367.

[8] Partride, E., Kreimer, A., Greenlee, R., Williams, C., Xu, J.L. and Church, T. (2009) Results from Four Rounds of Ovarian Cancer Screening in a Randomized Trial. Journal of Obstetrics Gynaecology, 113, 775-782. http://dx.doi.org/10.1097/AOG.0b013e31819cda77

[9] Macleod, U., Michell, E.D., Burgess, C., Macdonald, S. and Ramirez, A.J. (2009) Risk Factors for Delayed Presentation and Referral of Symptomatic Cancers: Evidence for Common Cancers. British Journal of Cancer, 101, s92-s101. http://dx.doi.org/10.1038/sj.bjc.6605398

[10] Andersen, B.L. and Cacioppo, J.T. (1995) Delayed in Seeking a Cancer Diagnosis: Delay Stages and Psychophysiological Comparison Processes. British Journal of Social Psychology, 34, 33-52. http://dx.doi.org/10.1111/j.2044-8309.1995.tb01047.x

[11] Lim, A.W., Ramirez, A.J., Hamilton, W., et al. (2014) Delays in Diagnosis of Young Females with Symptomatic Cervical Cancer in England: An Interview-Based Study. British Journal of General Practice, 64, e602-e610. http://dx.doi.org/10.3399/bjgp14X681757

[12] National Population Commission (NPC) [Nigeria] and ICF Macro (2009) Nigeria Demographic and Health Survey 2008. National Population Commission and ICF Macro, Abuja. 
[13] Eze, J., Umeora, O., Obuna, A., et al. (2012) Cervical Cancer Awareness and Cervical Screening Uptake at the Mater Misericodiae Hospital, Afikpo, Southeast Nigeria. Annals of African Medicine, 11, 238-243.

http://dx.doi.org/10.4103/1596-3519.102856

[14] Bukar, M., Takai, I.U. and Audu, B.M. (2012) Determinants of Utilization of Papanicolaou Smear among Outpatient Clinic Attendees in Northeastern Nigeria. African Journal of Medicine and Medical Sciences, 41, 183-189. 